\title{
O assentimento ao consentimento das crianças para participar em pesquisa clínica: por uma capacidade sanitária juridicamente reconhecida
}

\author{
Assent and consent for children's participation in clinical research: for a health \\ capacity legally recognized
}

\author{
Kalline Carvalho Gonçalves Eler* \\ Aline Albuquerque Sant'Anna de Oliveira ${ }^{* *}$
}

\section{Resumo}

\begin{abstract}
O presente artigo tem como objetivo problematizar o assentimento e o consentimento das crianças para participar em pesquisa clínica a partir do reconhecimento da sua capacidade sanitária. Trata-se de pesquisa teórica fundamentada no referencial dos Direitos Humanos das crianças e suas interpretações fornecidas pelo Comitê para os Direitos da Criança das Nações Unidas. Conclui-se que, no âmbito da pesquisa clínica, a capacidade legal, tal como disposta no Código Civil, revela-se inadequada, devendo ser substituída pela concepção de capacidade sanitária, de modo que o assentimento e o consentimento das crianças se tornem não apenas uma exigência ética, mas uma obrigação jurídica dos pesquisadores.
\end{abstract}

Palavras-chave: Capacidade civil. Capacidade sanitária. Assentimento. Consentimento. Ética em pesquisa. Direitos das crianças.

\section{Abstract}

\begin{abstract}
This article aims to problematize the assent and consent for children's participation in clinical research from the recognition of their sanitary capacity. It is a theoretical research based on the reference of children's human rights and their interpretations provided by the Committee for the Rights of the Child of the United Nations. It is concluded that in the scope of clinical research, the legal capacity as set out in the Civil Code is inadequate and should be replaced by the design of sanitary capacity so that children's assent and consent become not only an ethical requirement, but a legal obligation of researchers.
\end{abstract}

Keywords: Civil capacity. Sanitary capacity. Assent. Consent. Ethics in research. Children's rights.

\section{Introdução}

A participação das crianças em pesquisas é uma realidade que remonta ao século XVIII e persiste até os dias atuais (BOCANEGRA, 2010), sendo o assentimento da criança para participar de pesquisas exigência ética que se encontra na maioria das diretrizes nacionais e internacionais. No entanto, apesar da existência de regulações nesse sentido, verifica-se que não há consenso a respeito do que realmente constitui o assentimento, seus elementos e qual seria a idade mínima para assentir. Igualmente, não se observa, nas regulações existentes no Brasil e em países como os Estados Unidos, a possibilidade das crianças consentirem em pesquisa clínica, havendo apenas a previsão do assentimento.

Diante desse panorama, o presente artigo tem como objetivo problematizar o assentimento e o consentimento das crianças para participar em pesquisa clínica a partir do reconhecimento da sua capacidade sanitária.

Mestra em Direito pela Universidade Federal de Juiz de Fora. Doutoranda em Bioética pela Universidade de Brasília no Programa de Pós-graduação de Bioética da Universidade de Brasília. Professora de Direito Civil da Universidade Federal de Juiz de Fora. Brasília-DF-Brasil. E-mail: kalline. eler@ufj.edu.br.

Doutora em Ciências da Saúde pela Universidade de Brasília/Universidade de Zurique. Pós-Doutora em Direitos Humanos pela Universidade de Essex. Pós-Doutora em Direito Humano à Saúde pela Universidade de Emory. Professora de Bioética e Direitos Humanos do Programa de Pósgraduação de Bioética da Universidade de Brasília. Brasília-DF-Brasil. E-mail: alineaoliveira@hotmail.com. 
No âmbito dos cuidados em saúde e da pesquisa clínica, a capacidade legal, tal como disposta no Código Civil brasileiro de 2002, revela-se inadequada, posto que, estando ainda atrelada a uma competência cognitiva rígida e inflexível, expropria pacientes e participantes de pesquisa taxados como civilmente incapazes, e, por consequência, declarados inaptos para o exercício da autonomia em relação ao próprio corpo.

Neste artigo, adota-se o termo criança para os menores de 18 anos conforme a definição empregada pela Convenção sobre os Direitos da Criança (ONU, 1989) em seu primeiro artigo. No ordenamento jurídico brasileiro, esses menores são considerados incapazes e sua representação ou assistência legal estão, tradicionalmente, justificadas pela obrigação do Estado e da sociedade de protegê-los.

O dever de proteção, contudo, precisa ser conjugado com o princípio do melhor interesse e com o direito à participação, pois configuram princípios fundamentais que sustentam as demais provisões da Convenção e proveem uma estrutura forte para uma perspectiva centrada na criança, de acordo com Comentário Geral n. 5 (ONU, 2003).

Sendo assim, este artigo baseia-se em pesquisa teórica fundamentada no referencial dos Direitos Humanos das crianças e suas interpretações, fornecidas pelo Comitê para os Direitos da Criança das Nações Unidas, por meio de seus Comentários Gerais. Ainda foram utilizados artigos que versaram especificamente sobre $o$ assentimento de crianças na pesquisa.

Este artigo se inicia com a sintetização do percurso histórico da pesquisa envolvendo crianças, pois, apesar de esse tema ser amplamente abordado na literatura bioética quanto à pesquisa clínica em adultos, o mesmo não se pode dizer acerca dos acontecimentos que marcaram a ética em pesquisa envolvendo crianças.

Em seguida, passa-se a análise do direito à participação e do princípio do melhor interesse da criança, conforme o referencial constante da Convenção sobre os Direitos da Criança (ONU, 1989). Dando sequência, discorre-se sobre o conceito de capacidade sanitária e sua co-relação com o assentimento de crianças em ensaios clínicos.

\section{Síntese histórica da pesquisa clínica envolvendo crianças}

A pesquisa envolvendo crianças não era uma realidade até os séculos XVIII e XIX, quando se desenvolveu a Pediatria como especialidade médica. A maioria dos escritos encontrados no século XVI centrava-se em observações, costumes e sugestões baseadas em tentativa e erro. A fisiologia das crianças não era objeto de investigação e as taxas de mortalidade infantil e materna eram consideravelmente altas. Durante o século XVII, estudos dedicados ao tratamento das condições da infância começaram a surgir, e as faculdades de Medicina passaram a incluir a instrução em Pediatria no currículo. O século XVII também presenciou o início da pesquisa clínica moderna, que se fundamentava no estudo da doença pelo registro e a correlação de fenômenos clínicos, ou seja, na observação e estudo natural da doença (MORENO; KRAVITT, 2009; FLEISCHMAN, 2016).

Com o renascimento da Medicina, no século XVII, a partir, principalmente, da descoberta de William Harvey do sistema circulatório do sangue, foi possível, no século seguinte, o desenvolvimento da vacina de varíola a partir da inoculação de pequenas quantidades do vírus em crianças inglesas pobres altamente suscetíveis à doença. O experimento relacionado à varíola foi realizado, pela primeira vez, em 1796, por Edward Jenner, que conduziu seu famoso ensaio de vacinação usando varíola bovina em seu filho de um ano de idade e, posteriormente, em outras crianças da sua comunidade (MORENO; KRAVITT, 2009; BOCANEGRA, 2010). Jenner descreveu seu trabalho como altamente benéfico, particularmente para as famílias, e, embora tenha reconhecido a presença de riscos e adotado medidas a fim de minimizá-los, não se sentiu incomodado com o uso de crianças em uma experimentação, pois seu objetivo era criar uma vacina que melhoraria a vida de milhares de crianças (FLEISCHMAN, 2016).

A Pediatria tornou-se uma especialidade médica oficialmente reconhecida no século XIX, quando, na década de 1880, as sociedades médicas nos Estados Unidos e da Europa instituíram as seções pediátricas. 
O interesse crescente pela saúde infantil levou à criação de hospitais pediátricos que, junto aos orfanatos, forneciam aos pesquisadores uma população de crianças aptas para a pesquisa. Em razão da ocorrência de surtos de doenças em muitas dessas instituições, as crianças residentes eram incluídas em investigações clínicas, usualmente, sem a obtenção da sua concordância ou de responsáveis. Cabe assinalar que se constata, nesse momento histórico, a presença de raras objeções no âmbito da comunidade médica em relação à pesquisa envolvendo crianças institucionalizadas. Isto pode ser explicado pelo fato de que a maioria dos pesquisadores considerava que os benefícios da pesquisa superavam os riscos potenciais para as crianças (FLEISCHMAN, 2016, p.198).

As pesquisas envolvendo crianças continuaram no século $\mathrm{XXe}$, tal como no período anterior, seu foco recaia sobre as doenças transmissíveis que se espalhavam rapidamente nas instituições (varíola, molusco contagioso, tuberculose, coqueluche, sarampo e poliomelite). Ademais, registra-se que novas pesquisas envolvendo crianças objetivaram investigar novas técnicas de diagnóstico, tais como punção lombar ou observação da fisiologia da criança de estômago vazio, e ambas buscavam compreender as diferenças entre as crianças e os adultos. No entanto, em contraste com Jenner, pesquisador do século XVIII, os pesquisadores da primeira década de 1900 raramente discutiam os riscos ou o desconforto associados à pesquisa, e não manifestavam preocupações éticas com o uso de crianças em pesquisa, as quais, na sua maioria, eram pobres ou abandonadas em orfanatos (MORENO; KRAVITT, 2009; FLEISCHMAN, 2016).

Com o início da Segunda Guerra Mundial, verifica-se que o intuito de incrementar o bem-estar dos soldados em batalha impulsionou a realização de pesquisas envolvendo crianças. Os países das Forças Aliadas e do Eixo expandiram a pesquisa exponencialmente durante todo esse período, e como exemplo tem-se a realização de experimentos em crianças e adultos internos em campos de concentração nazistas, os quais, muitas vezes, resultavam em sofrimento extremo, incapacidade e na morte dos participantes da pesquisa (MORENO; KRAVITT, 2009, p. 55).

Após a Segunda Guerra Mundial, em 1947, vinte e três médicos nazistas foram julgados por um Tribunal instituído pelos Estados Unidos em Nuremberg, Alemanha, por crimes cometidos sob a forma de experiências médicas em campos de concentração. Ao final do julgamento, os juízes de Nuremberg formularam dez princípios sobre a ética em pesquisa envolvendo seres humanos, os quais foram denominados como Código de Nuremberg. Destaca-se o primeiro princípio, de acordo com o qual o consentimento voluntário do ser humano é absolutamente essencial e esse consentimento é válido apenas se a pessoa envolvida tiver capacidade legal. Sendo assim, pode-se considerar que, a partir desse princípio, as pesquisas envolvendo crianças e outros indivíduos incapacitados não seriam eticamente aceitáveis, todavia isso foi ignorado pelos Estados Unidos, e as pesquisas envolvendo crianças continuaram até a década de 70, sem qualquer tentativa real de regulação (FLEISCHMAN, 2016).

Em 1954, estudos conduzidos em Willowbrook, escola e lar de crianças com deficiência mental em Nova York, ocasionaram a infecção deliberada de crianças saudáveis com hepatite viral para se estudar o curso natural da doença e desenvolver uma profilaxia. Willowbrook se encontrava superlotado e insalubre, fatores que impulsionaram a transmissão da hepatite e sua incidência nas crianças residentes (MORENO; KRAVITT, 2009, p. 55).

Em 1932, dá-se início, em Tuskegee, Alabama, ao estudo da progressão natural da sífilis em 400 homens negros, que durou 40 anos. Os doentes envolvidos no caso, além de não terem sido informados sobre seu diagnóstico, jamais consentiram ou receberam qualquer tratamento, embora já existente na época do estudo. O experimento médico realizado pelo Serviço Público de Saúde dos Estados Unidos, apesar de não envolver crianças, trouxe para o debate público o tema da exploração das populações vulneráveis no ambiente da pesquisa.

A partir da repercussão midiática dos casos Willowbrook e Tuskegee, na década de 70 , comitês de ética em pesquisa foram criados nos Estados Unidos e em outros países, bem como importantes documentos acerca da regulação ética da pesquisa envolvendo seres humanos foram adotados, tais como a primeira versão da Declaração de Helsinque, adotada pela Associação Médica Mundial em 1964, e o Relatório Belmont, em 1978, resultando em princípios éticos norteadores da pesquisa biomédica com seres 
humanos, quais sejam: a) o princípio do respeito às pessoas, que se traduz em duas assertivas - de que os indivíduos devem ser tratados como agentes autônomos, e que as pessoas com autonomia reduzida devem ser protegidas; b) o princípio da beneficência, que exige, em primeiro lugar, "não causar dano" e, em segundo, a maximização dos possíveis benefícios e minimização dos possíveis danos; c) o princípio da justiça, entendido como a justa distribuição do ônus e bônus da pesquisa.

Os eventos abordados neste tópico revelam que os interesses e direitos das crianças envolvidas nas pesquisas não foram considerados em primeiro plano, além de muitas terem sido submetidas à situação exploratória por parte dos pesquisadores. Observa-se que as crianças eram vistas como objeto de pesquisa, ou seja, não eram consideradas como sujeitos titulares de direitos ou agentes morais aptos a fazer escolhas relacionados à sua participação em pesquisas clínicas. A alteração dessa concepção somente foi revista, no âmbito internacional, a partir da entrada em vigor da Convenção sobre os Direitos da Criança, adotada pela Organização das Nações Unidas - ONU em 1989 (ONU, 1989), primeiro instrumento internacional a reconhecer explicitamente a criança como titular de direitos humanos.

A Convenção consagra, no artigo 3.1, o princípio do melhor interesse e, no artigo 12, o direito de participação de acordo com a capacidade progressiva da criança. Dada a relevância desses princípios para a adequada compreensão da Convenção e a sua efetivação, o Comitê para os Direitos da Criança editou um Comentário Geral, separadamente, para cada um deles, os quais serão objeto de análise no próximo item.

\section{0 direito da criança à participação em pesquisa clínica e o princípio do melhor interesse}

A Convenção sobre os Direitos da Criança (ONU, 1989) estabeleceu normas vinculantes sobre temas que, anteriormente, eram regulados apenas por recomendações e introduziu uma abordagem centrada na criança, no âmbito do Direito Internacional dos Direitos Humanos, ao prescrever que os interesses das crianças sejam considerados prioritariamente e que devem participar da tomada de decisões sobre temas que Ihes sejam afetos.

Os princípios centrais da Convenção sobre os Direitos da Criança (ONU, 1989), conforme o Comentário Geral ${ }^{1}$ n. 5 (ONU, 2003), estão expressos nos: artigo 2 (princípio da não-discriminação); artigo 3.1 (princípio do melhor interesse); artigo 6 (direito à vida, sobrevivência e desenvolvimento); artigo 12 (direitos de participação de acordo com a capacidade progressiva). Esses quatro princípios gerais sustentam as demais provisões da Convenção (ONU, 1989) e proveem uma estrutura sólida para uma abordagem centrada na criança. Em razão da sua maior pertinência para a análise do assentimento da criança no bojo da pesquisa clínica, o direito à participação e o princípio do melhor interesse serão abordados neste artigo.

Com o objetivo de conferir conteúdo ao artigo $12^{2}$ da Convenção, de modo a estimular sua aplicação concreta pelos Estados, o Comitê sobre os Direitos da Criança da ONU editou o Comentário Geral n. 12 (ONU, 2009). O documento explicita que os Estados não devem partir da premissa de que a criança é incapaz de expressar suas opiniões, antes devem ter por pressuposto que a criança tem capacidade para formar suas próprias opiniões e o direito de expressá-las. Assim, os Estados têm o dever de assegurar que a criança receba informação adequada e o apoio necessário para tomar uma decisão em consonância com o seu melhor interesse.

Ainda que a Convenção (ONU, 1989) não utilize expressamente o termo participação, o Comitê reconhece ser esse o melhor termo para expressar o conteúdo do artigo 12. A participação coloca em relevo que a inclusão das crianças no processo de tomada de decisão não deve ser apenas um ato isolado,

Desde a adoção da Convenção sobre os Direitos da Criança pela Assembleia Geral das Nações Unidas, o Comitê para os Direitos da Criança tem divulgado uma série de Comentários Gerais que visam fortalecer e fornecer uma melhor compreensão do significado da Convenção e suas implicações para os governos, partes interessadas, organizações não governamentais (ONGs) e a sociedade em geral.

2 Os Estados Partes devem assegurar à criança que é capaz de formular seus próprios pontos de vista o direito de expressar suas opiniões livremente sobre todos os assuntos relacionados a ela, e tais opiniões devem ser consideradas, em função da idade e da maturidade da criança. 2 - Com tal propósito, proporcionar-se-á à criança, em particular, a oportunidade de ser ouvida em todo processo judicial ou administrativo que afete a mesma, quer diretamente quer por intermédio de um representante ou órgão apropriado, em conformidade com as regras processuais de legislação nacional. 
mas compreende a troca de ideias, opiniões e entendimentos entre a criança e os outros participantes do processo de tomada de decisão acerca da sua condição.

Embora a Convenção (ONU, 1989) não trate especificamente do tema da pesquisa envolvendo crianças, com base no preceituado no artigo 12, sustenta-se o direito à participação da criança no processo de tomada de decisão acerca da sua inclusão em uma pesquisa clínica, pois o dispositivo consagra o direito da criança expressar suas visões e participar das decisões que digam respeito à sua vida, o que inclui questões não mencionadas explicitamente na Convenção, como a participação em pesquisa clínica.

O artigo 12 não apenas estabelece o direito da criança de opinar sobre todos os assuntos que a afetam, mas também institui um valor fundamental que serve de vetor interpretativo para os demais direitos consagrados na Convenção.

A Convenção sobre os Direitos da Criança define criança como sendo uma pessoa com capacidade em progresso e que, apesar da sua autodeterminação não ser completa em razão da sua imaturidade emocional, capacidade cognitiva e dependência, não é inexistente e há que ser reconhecida e valorizada. $A$ Convenção (ONU, 1989) reconhece, assim, a criança como um ser humano com integridade, personalidade e habilidade para desempenhar um papel ativo na sociedade, o que inclui o direito de participar em pesquisa clínica (CLARKE, 2015).

A participação em ensaios clínicos, entretanto, envolve não apenas o direito de escolher fazer parte ou não de uma pesquisa, mas também o direito de ser informado. Sendo assim, o direito à participação abarca o direito de ser ouvido, de ter sua percepção, preferências e escolhas respeitadas. Em suma, ser verdadeiramente envolvido na tomada de decisão acerca da sua própria participação.

Ademais, ressalte-se que a participação da criança no processo de tomada de decisão é fundamental para que a definição dos seus melhores interesses considere a ótica da própria criança. Assim, a participação da criança, de acordo com o Comitê, está conectada como todos os demais artigos da Convenção que não podem ser aplicados integralmente se não respeitarem a criança como sujeito com opiniões próprias. A participação permite, especialmente, a realização de direitos como o direito à liberdade de expressão e o direito à liberdade de pensamento, de consciência e de crença; e, na grande maioria dos casos, proporciona o alcance da melhor decisão, além de desenvolver a capacidade da criança para exercer sua autonomia pessoal.

Em relação ao princípio do melhor interesse, com o objetivo de densificá-lo, o Comitê sobre os Direitos da Criança das Nações Unidas editou, em 2013, o Comentário Geral n. 14 (ONU, 2013), que apresenta o interesse superior da criança como sendo um conceito de natureza tripla: (a) direito substantivo: o direito das crianças de que o seu interesse seja considerado primordial quando diferentes interesses estejam em consideração, bem como a garantia de que esse direito será tomado em conta sempre que se tenha que tomar uma decisão que afete uma criança, um grupo de crianças ou as crianças em geral. Esse direito substantivo cria uma obrigação imediata para os Estados, pois o direito à consideração primeira é autoexecutável e pode ser invocado perante um tribunal; (b) princípio jurídico fundamental interpretativo: se uma disposição jurídica permitir mais de uma interpretação, deverá ser escolhida aquela que efetivamente melhor satisfaça o interesse superior da criança; (c) regra processual: sempre que é tomada uma decisão que afeta uma criança, um grupo de crianças ou as crianças em geral, o processo de tomada de decisão deve incluir uma avaliação do impacto positivo ou negativo, da decisão sobre a criança ou das crianças envolvidas.

Além disso, a fundamentação de determinada decisão sobre uma criança ou um grupo de crianças deve indicar qual direito foi considerado. Logo, os Estados devem explicar como o direito identificado foi respeitado na decisão, ou seja, o que foi considerado como sendo do interesse superior da criança, quais critérios fundamentaram a decisão e como se procedeu à ponderação do interesse da criança em face de outros interesses.

Ainda, o Comitê apresenta uma lista detalhada de fatores que deverão orientar o Estado no momento de avaliar e determinar o melhor interesse da criança, quais sejam: a opinião da criança; a identidade da criança; preservação do ambiente familiar e manutenção de relações; cuidados, proteção e segurança da 
criança; situação de vulnerabilidade; o direito da criança à saúde; e o direito da criança à educação. Tratase de uma lista não exaustiva, sendo possível sua expansão a fim de incluir outros fatores relevantes para determinada criança ou grupo de crianças.

O melhor interesse da criança no contexto da pesquisa clínica deve conjugar proteção e autodeterminação, que se materializa por meio do seu assentimento. Assim, o envolvimento da criança em qualquer pesquisa, independente da sua natureza, somente será ética e juridicamente aceitável caso se amolde ao seu melhor interesse. Isto significa que a pesquisa deve resultar em benefícios diretos para a saúde da criança, sendo excepcionais as pesquisas sem potencial benefício direto, de acordo com o artigo 7 da Declaração Universal sobre Bioética e Direitos Humanos (UNESCO, 2005). Esse artigo prevê que a autorização para pesquisa seja sempre obtida no melhor interesse dos indivíduos incapazes para fornecer consentimento.

A participação das crianças, como enfatiza o Conselho das Organizações Internacionais de Ciências Médicas (CIOMS, 2016), é indispensável para pesquisas de doenças da infância e das condições às quais elas estão particularmente suscetíveis. A participação das crianças em pesquisas pode, por exemplo, evitar que elas sejam submetidas a tratamentos médicos ineficazes ou prejudiciais. No entanto, ainda que a participação da criança na pesquisa represente o seu melhor interesse, essa participação deve se dar de forma a permitir o desenvolvimento da sua autodeterminação. A Declaração da UNESCO (2005), com essa preocupação, determina que os indivíduos incapazes sejam envolvidos no processo de decisão, na medida do possível, e ainda prescreve que a recusa de tais indivíduos em participar de pesquisas deve ser respeitada.

Igualmente, as Diretrizes Éticas Internacionais para Pesquisa Biomédica envolvendo Seres Humanos, no que diz respeito à criança, estabelece que o assentimento de cada criança deve ser obtido na medida da sua capacidade e que sua recusa em participar ou continuar na pesquisa deve ser respeitada, a menos que a participação seja considerada a melhor opção médica (CIOMS, 2016).

No Brasil, a participação das crianças em ensaios clínicos se encontra prevista na Resolução 466, de 2011, do Conselho Nacional de Saúde que, todavia, não a pormenoriza, bem como a despeito de mencionar o assentimento da criança, não prevê em qual idade deve ser exigido e como será obtido. A título de comparação, com o intuito de demonstrar a incipiência da legislação brasileira, que é única para todos os participantes de pesquisa, a legislação americana, por exemplo, regula a pesquisa envolvendo crianças de forma apartada da legislação geral. O regulamento federal dos Estados Unidos da pesquisa envolvendo crianças é dividido em quatro categorias nas quais a pesquisa é permitida. Primeiro, a pesquisa com crianças é autorizada se o risco envolvido não é maior que o mínimo, independentemente de haver a perspectiva de benefício direto para a criança. Em segundo lugar, a pesquisa é permitida se há uma perspectiva de benefício direto para a criança, desde que os riscos sejam minimizados e justificados pelo nível do benefício antecipado. Em terceiro lugar, a pesquisa é permitida mesmo se envolver um risco maior e não houver perspectiva de benefício individual para a criança, desde que o nível de risco consista em pequeno aumento sobre o mínimo tolerável e a pesquisa seja apta a gerar informações de importância vital sobre a condição de saúde da criança. Em quarto lugar, autoriza-se a pesquisa que não se enquadra nas primeiras três categorias, mas apresenta uma oportunidade para entender, prevenir ou aliviar um problema grave que afeta a saúde ou bem-estar da criança (FLEISCHMAN, 2016).

Uma vez esclarecido como se interpretam o direito à participação e o princípio do melhor interesse da criança, segundo as orientações do Comitê para os Direitos da Criança, que devem ser aplicadas no contexto da pesquisa clínica, cabe, agora, analisar os modelos de capacidade sanitária.

\section{Capacidade sanitária}

A capacidade sanitária diz respeito à capacidade para tomar decisões no âmbito da saúde e, segundo Albuquerque (2016), fundamenta-se em três modelos: o de direitos humanos, o do menor maduro e o da competência Gillick. O modelo de direitos humanos, apresentado anteriormente, consoante o artigo 12 da Convenção Sobre Direitos da Criança (ONU, 1989), assenta-se no direito da criança que é capaz de 
formular seus próprios juízos, de expressar suas opiniões livremente sobre todos os assuntos relacionados a si mesma.

O modelo do menor maduro, em termos gerais, tem sua origem nos Estados Unidos e, nesse país, pode ser aplicado segundo três propostas: a) a partir de determinada idade; que pode ser 14, 15, 16, 18 anos, ou ter completado o Ensino Médio. A depender da lei do Estado, o adolescente pode consentir ou recusar sem se avaliar sua maturidade; b) o menor de determinada idade, 16 anos, ou que seja maduro e capaz de consentir pode fazê-lo apenas se seus responsáveis não estiverem disponíveis ou não desejarem consentir; c) todos os menores que forem maduros e capazes de consentir, a despeito da idade, podem expressar sua vontade e será vinculante (ALBUQUERQUE, 2016).

O terceiro modelo é resultado de uma decisão tomada pela Suprema Corte inglesa, no ano de 1986, em que uma mãe chamada Victoria Gillick, opondo-se a uma circular do departamento de saúde local que autorizava os médicos a prescreverem contraceptivos aos menores de 16 anos sem o consentimento dos pais, solicitou às autoridades sanitárias que suas filhas não viessem a receber contraceptivos ou tivessem eventual gravidez interrompida sem que ela fosse informada. Diante da negativa das autoridades locais em atender à sua solicitação, a Sra. Gillick ajuizou uma ação que não obteve êxito. A decisão proferida no caso foi no sentido de que os médicos, agindo no melhor interesse da criança, poderiam prescrever contraceptivos se a criança fosse competente e consentisse para tanto. Isso seria possível, independentemente da vontade dos pais, em prol do direito da criança à privacidade (HERRING, 2011).

A competência Gillick assegura o direito dos menores de 16 anos consentirem com tratamentos médicos se apresentarem capacidade para tanto. Sendo assim, para ser considerada capaz, a criança deve compreender problemas médicos relevantes; deve ter uma visão própria e não apenas refletir os pontos de vista de outros; deve compreender as questões morais e familiares envolvidas, bem como as questões médicas; deve apresentar uma capacidade estável, ou seja, sua aptidão para compreender os diversos fatores concernentes à tomada decisão não pode ser flutuante. Por fim, não pode o tribunal inferir a incapacidade por considerar a decisão da criança incorreta (HERRING, 2011).

No contexto brasileiro, a mera observância da capacidade legal da criança, nos termos do Código Civil, para a tomada de decisão acerca da sua participação em pesquisa clínica é insuficiente, pois tal instituto foi concebido, originariamente, para protegê-la em questões de natureza patrimonial, logo não se revela adequado para as especificidades do cuidado terapêutico e da pesquisa clínica, que envolvem questões não patrimoniais.

A inflexibilidade do conceito de capacidade civil, cunhado em um contexto de excessiva preocupação com a proteção do patrimônio, produz efeitos negativos em relação aos participantes de pesquisa considerados juridicamente incapazes ao retirar-Ihes a autonomia para decidir sobre seu próprio corpo.

Percebe-se, dessa maneira, a necessidade de uma releitura bioética do instituto da capacidade legal, a fim de conferir o direito à participação da criança no processo de tomada de decisão em pesquisa. Para tanto, torna-se necessário compreender melhor os instrumentos que concretizam a participação da criança em ensaios clínicos: assentimento e consentimento.

\subsection{Assentimento da criança em pesquisa clínica}

Na tentativa de transpor os obstáculos jurídicos impostos pelo regime de capacidade civil, desenvolveu-se paulatinamente a noção de assentimento, que deve ser vista não apenas como uma exigência ética, mas também jurídica, assentada no direito à participação da criança e no princípio dos melhores interesses.

Diante da ausência de um consenso internacional acerca do assentimento, Tait e Geisser (2017), utilizando o método Delphi, ${ }^{3}$ reuniram vários especialistas em pesquisa pediátrica, bioética, membros de

Trata-se de um processo estruturado para coletar e refinar o conhecimento de um grupo de especialistas por meio de uma série de questionários intercalados com feedback de opinião controlada. Tem sido usado extensivamente em saúde pública como meio de obter consenso (TAIT; GEISSER, 2017). 
comitês de ética, pais e indivíduos com experiência em regulação legal para construir uma definição. A versão final alcançada pelos autores foi no seguinte sentido: crianças que não têm capacidade legal para consentir, com base em leis estaduais, ${ }^{4}$ devem fornecer assentimento para participar de uma pesquisa, a menos que a falta a habilidade cognitiva e sua condição clínica a impeçam de comunicar sua escolha, ou que a pesquisa apresente benefício direto disponível apenas para quem for participante.

O assentimento é um processo interativo entre pesquisador e criança participante que envolve a divulgação de informações cognitivas e emocionalmente apropriadas em relação a, no mínimo, porque a criança está sendo convidada a participar, uma descrição dos procedimentos e como a criança pode experimentá-los, e uma compreensão de que a participação no estudo é voluntária. As crianças devem entender que podem recusar a participação ou retirar-se do estudo a qualquer momento. $O$ assentimento exige que a criança afirme explicitamente sua concordância para participar de uma maneira que reflita uma compreensão apropriada à idade e que é livre de influência indevida ou coerção. Não havendo uma concordância explícita, a ausência de objeção da criança não pode ser interpretada como assentimento (TAIT; GEISSER, 2017).

Considerando a definição de assentimento formulada pela pesquisa de Tait e Geisser (2017), adotada neste artigo, entende-se que o assentimento está vinculado à maturidade da criança. Por maturidade, entende-se, de acordo com o Comitê para os Direitos da Criança, a capacidade de compreender e avaliar as consequências de uma determinada questão, ou seja, é a capacidade da criança expressar suas opiniões sobre os assuntos de maneira razoável e independente, não sendo exigido para tanto profundidade de compreensão.

No contexto brasileiro, o assentimento é definido pela Resolução 466/2012, do Conselho Nacional de Saúde, da seguinte forma:

anuência do participante da pesquisa, criança, adolescente ou legalmente incapaz, livre de vícios (simulação, fraude ou erro), dependência, subordinação ou intimidação. Tais participantes devem ser esclarecidos sobre a natureza da pesquisa, seus objetivos, métodos, benefícios previstos, potenciais riscos e o incômodo que esta possa lhes acarretar, na medida de sua compreensão e respeitados em suas singularidades. (BRASIL, 2012).

O assentimento, tal como o consentimento, é um processo contínuo que busca envolver a criança na tomada de decisão através da divulgação das informações principais e dos procedimentos em linguagem adequada, e da manifestação por parte da criança de suas preferências. O assentimento configura o meio pelo qual a criança exerce o seu direito à participação no contexto da pesquisa clínica, e revela-se de extrema importância, pois, além de incluir a criança na pesquisa como participante, estabelece uma relação de confiança entre criança, pesquisadores e responsáveis legais, reduzindo os riscos de coerção e exploração. No processo de assentimento, a criança tem a possibilidade de externar sua perspectiva, preferências e desejos, viabilizando, assim, a realização do seu melhor interesse. Enquanto o alcance do melhor interesse da criança é o objetivo que deve nortear todas as ações, públicas ou privadas, concernentes à criança; a participação é o método pelo qual se alcança esse objetivo.

Nesse sentido, embora não haja consenso quanto à idade mínima para subscrever o assentimento (BAINES, 2011), o assentimento para participar em ensaios clínicos é exigência ética que se encontra na maioria das diretrizes nacionais e internacionais. ${ }^{5}$

Outlon et al. (2016) propõem um modelo de avaliação personalizada da capacidade de assentir que considere a idade, habilidade cognitiva e estado de saúde da criança, bem como a visão dos pais sobre a participação da criança. O modelo conceitual proposto envolve quatro domínios que devem ser considerados pelos pesquisadores para que haja um assentimento adequado: fatores relacionados à criança (capacidade

A referência aqui diz respeito à organização legislativa dos Estados Unidos, que permite a normatização da matéria pelos estados.

A título de exemplo, cita-se o Código de Regulação Federal 45, parte 46 dos Estados Unidos (45 CFR 46), Diretrizes do Colégio Real de Pediatria e Saúde Infantil do Reino Unido, Diretrizes da ética em pesquisa da África do Sul, Conselho das Organizações Internacionais de Ciências Médicas (CIOMS). Desde 2000, por ocasião da $5^{a}$ revisão, a Declaração de Helsinque reconhece o assentimento como parte fundamental da ética em pesquisa pediátrica. 
intelectual, nível de consciência, idioma falado, forma de comunicação, nível de literalidade, estado de saúde, conhecimento da condição de saúde, bem-estar psicológico e maturidade); à dinâmica familiar (nível de concordância com a família, responsabilidade parental e questões culturais), ao desenho do estudo e complexidade (o que é exigido, riscos e benefícios, ônus da pesquisa e pesquisas prévias), à pesquisa e fatores organizacionais (cultura, experiência, ferramentas, tempo e treinamento).

O modelo proposto por Outlon et al. (2016) busca superar as dificuldades conceituais em torno do assentimento, a fim de torná-lo uma ferramenta prática dos pesquisadores no momento de aferição e aperfeiçoamento da capacidade de assentir da criança, o que levará em conta a conjugação dos diversos fatores mencionados, e não apenas a sua idade. Embora a idade ofereça aos pesquisadores um critério mais exato e, portanto, melhor do ponto de vista operacional de acordo com os autores, esse critério, isoladamente, é insuficiente, pois desconsidera, por exemplo, a experiência pessoal da criança com a doença e sua maturidade crescente, nem sempre atrelada a sua idade biológica. Assim, consoante esse modelo, a única hipótese em que o assentimento não se aplica e os pais decidem se dá quando, a despeito de todos os esforços empreendidos, a criança não consegue comunicar sua escolha quanto à participação ou não na pesquisa.

A avaliação da capacidade das crianças pelos pesquisadores, contudo, é problemática, haja vista a posição de parcialidade que os mesmos se encontram. Transferir essa avaliação para os comitês de ética também acarretaria ônus, pois os membros, além de não terem contato direto com os participantes quando da análise dos protocolos de pesquisa, trabalham voluntariamente em países como o Brasil.

Tem-se propugnado internacionalmente a idade de 7 anos para assentir. Em relação ao menor de 7 anos, ainda que não venha a manifestar-se por escrito em relação ao seu assentimento, será ouvido, e sua opinião tomada com a devida consideração (ALBUQUERQUE, 2016). Esse é o entendimento que melhor se coaduna com o respeito ao direito da criança de ser escutada em todos os assuntos que venham a afetá-la. O artigo 12 da Convenção sobre os Direitos da Criança (1989) não impõe limite de idade ao direito da criança de expressar sua opinião, e o Comitê sobre os Direitos da Criança desaconselha os Estados a introduzir, por lei ou na prática, limites de idade que restrinjam o direito de ser escutado.

Ao mesmo tempo, o Comitê sublinha a necessidade de legislação que estabeleça uma idade fixa para o consentimento no âmbito sanitário, a fim de que as crianças, a partir da idade estabelecida, tenham o direito de outorgar o seu consentimento sem o requisito da avaliação individual de sua capacidade por um profissional (ONU, 2009). Não obstante, o Comitê recomenda que os Estados garantam que, quando a criança tiver idade inferior à estabelecida, mas demonstrar capacidade para expressar sua opinião com conhecimento de causa sobre o tratamento, tome-se devidamente em conta essa opinião. Embora o Comitê ainda não tenha emitido comentários sobre a pesquisa envolvendo crianças, e ainda que haja peculiaridades entre o tratamento e a pesquisa, tendo em vista que os objetivos que orientam as condutas dos profissionais são diversos - no primeiro, o cuidado e o pressuposto da beneficência, e no segundo, a descoberta e o risco -, ainda assim, a opinião da criança é relevante para sua participação em pesquisa, pois nessa também haverá a manipulação do seu corpo. Dessa forma, seja no âmbito dos cuidados terapêuticos, seja no campo da pesquisa, a criança tem o direito de opinar sobre aquilo que a afeta diretamente.

Baines (2011) argumenta que ainda não existe uma definição clara do que seja o assentimento e uma justificativa plausível para sua utilização, por essa razão, diante da confusão em torno do conceito de assentimento, o autor sustenta a sua supressão das diretrizes existentes. Em seu lugar, propõe o simples reconhecimento de que crianças competentes devem consentir e que, no caso das crianças incompetentes, ou seja, daquelas que não têm capacidade para consentir, as decisões devem ser tomadas pelos pais ou responsáveis. $\mathrm{O}$ autor, entretanto, deixa em aberto o que seria uma criança competente e quais critérios poderiam ser empregados para aferir sua capacidade. Além disso, Baines (2011) não nega a necessidade de envolvimento da criança na deliberação acerca da pesquisa, mas conclui que, para evitar conflitos, a decisão final deve ser dos pais; não tendo, portanto, o envolvimento qualquer valor ético-jurídico, o que se revela contraditório. $\mathrm{O}$ autor compreende que o assentimento pode causar conflitos no contexto familiar na hipótese de dissenso, pois prevalecerá a decisão da criança ou dos pais e, nesse caso, o assentimento 
torna-se desnecessário, uma vez que, justamente nos momentos mais importantes - qual seja, a hipótese de desacordo -, a criança é, tradicionalmente, submetida à vontade dos pais, não tendo o assentimento efeito algum.

A despeito da correta percepção quanto à necessidade de precisar o conceito de assentimento, o autor ignora que o possível conflito entre pais e criança não deixará de existir apenas porque o assentimento foi suplantado. $O$ assentimento revela-se fundamental, pois não sendo possível uma solução satisfatória em conjunto, o dissenso da criança deve ser respeitado, salvo quando houver grave prejuízo à sua saúde.

Sem o respeito ao dissenso da criança, o assentimento não tem sentido. Em muitos casos, as crianças não sabem efetivamente se a participação da pesquisa será angustiante até que elas experimentem. Os pesquisadores, portanto, precisam estar atentos a qualquer sinal indicativo de retirada, tais como olhar disperso, demora em responder, fadiga, e conscientes dos desejos e sentimentos dos participantes. $O$ assentimento não se esgota em um único evento e, por isso, deve-se, periodicamente, reavaliar o desejo da criança em participar da pesquisa.

Não há na normativa brasileira nenhuma indicação de como os pesquisadores deverão proceder na ocorrência de conflito entre a opinião da criança e o consentimento dos pais. A legislação americana, a seu turno, aceita a dispensa do assentimento quando a pesquisa oferece um risco mínimo ou quando, apesar de envolver um risco maior, oferece uma perspectiva de benefício direto que é importante para a saúde ou bem-estar da criança e encontra-se disponível apenas no contexto da pesquisa. Nessa situação, o benefício deve advir diretamente da pesquisa em si e não dos benefícios colaterais associados à participação na pesquisa. Além disso, a disposição de cuidados clínicos não disponíveis para a criança ou a compensação monetária pela participação na pesquisa, por si só, não constituem benefícios que justifiquem a exposição do participante a riscos maiores que o mínimo (FLEISCHMAN, 2016).

Embora o assentimento careça de diretrizes claras para sua adequada aplicação no contexto da pesquisa no Brasil, não utilizá-lo seria uma violação ao direito de participação, e por conseguinte, ao princípio do melhor interesse, já que, consoante o Comitê para os Direitos da Criança, não é possível uma aplicação correta do artigo 3 sem respeitar os componentes do artigo 12 da Convenção sobre os Direitos da Criança (ONU, 1989), o que significa dizer que participação e melhor interesse são preceitos complementares.

Se, quanto ao assentimento da criança, já é possível considerar que avanços significativos ocorreram, o mesmo não se pode dizer acerca do consentimento informado das crianças, tema ainda pouco enfrentado pela literatura bioética e pelas legislações.

\subsection{Consentimento informado: a capacidade sanitária das crianças}

O consentimento informado expressa o exercício da autodeterminação dos participantes da pesquisa e justifica-se não somente para minimizar potenciais danos, mas precipuamente para proteger o direito à privacidade do participante. No caso das crianças, como explicado, por serem consideradas juridicamente incapazes, o consentimento é dado pelos pais ou por outro representante legal, cabendo à criança o assentimento.

Inferem-se dois sentidos do consentimento informado: um sentido substancial, que implica a autorização para a participação em pesquisa externada por um indivíduo autônomo que, além de expressar sua aquiescência com a proposta, deve estar devidamente informado e agir voluntariamente; e um sentido formal, referente à conformidade com as regras exigidas dos profissionais para obter um consentimento legal ou institucionalmente válido dos participantes de pesquisa (BEUACHAMP; CHILDRESS, 2013). Assim, uma criança pode consentir, no primeiro sentido, mas tal consentimento não apresenta suporte jurídico. Adotando-se o segundo sentido, a criança não pode consentir, ainda que demonstre ter habilidades para tanto e, por isso, para tomar em consideração a sua opinião, adota-se seu assentimento informado.

A capacidade para consentir pode ser aferida no caso concreto a partir de quatro habilidades, a saber: compreender, reter informações, sopesar as informações e comunicar sua decisão (DONNELLY, 2010). 
A compreensão não precisa ser completa, mas deve ser coerente quanto aos fatos centrais e relevantes relacionados à decisão que irá ser tomada. Isso significa que o participante da pesquisa deve entender as consequências previsíveis de se decidir participar ou não. A habilidade para reter a informação permite processar intelectual e emocionalmente, durante o processo decisional, as consequências da participação. $\mathrm{Na}$ esteira, sopesar riscos e benefícios revela a capacidade de raciocínio (raciocínio consequencial, raciocínio comparativo e consistência lógica). Quanto à possibilidade de comunicar a decisão (seja oralmente, usando linguagem de sinais ou qualquer outro meio), trata-se mais de um requisito prático, posto que a impossibilidade total de comunicação inviabiliza a concretização da decisão tomada (DONNELLY, 2010). Tendo isso em vista, advoga-se, neste artigo, pela possibilidade do consentimento informado, e não apenas assentimento das crianças, em consonância com o sentido substancial dessa categoria.

Em relação aos procedimentos e potenciais riscos e benefícios da participação em pesquisa, as crianças são, surpreendentemente, competentes para entender, algo ignorado pelo regime da capacidade civil. Kuther e Posada (2004) citam vários estudos que demonstram a aptidão da maioria das crianças acima de 7 e 8 anos para compreender informações concretas a respeito dos procedimentos desenvolvidos na pesquisa. ${ }^{6}$

Em relação à habilidade de usar as informações e pesar riscos e benefícios concernentes às diferentes opções para fazer uma escolha, Kuther e Posada (2004) apresentam estudos que demonstram o surgimento dessa habilidade no final da infância e início da adolescência, ou seja, a partir dos 12 ou 13 anos. É nesse período que as crianças passam a raciocinar abstratamente sobre situações hipotéticas, múltiplas alternativas e consequências, bem como a combinar múltiplas variáveis de forma mais complexa e a examinar a informação de uma maneira sistemática e exaustiva.

No que tange às influências externas que impactam a habilidade de mensurar os efeitos futuros da decisão, Kuther e Posada (2004) concluíram que a maioria das crianças entre 8-11 anos, em virtude da imaturidade social e emocional, tem dificuldades para entender o direito de se retirar da pesquisa, em razão da autoridade com que enxergam os pais e os pesquisadores.

As assertivas apresentadas por Kuther e Posada (2004) assemelham-se em muitos aspectos à pesquisa empírica desenvolvida por Hein et al. (2015a; 2015b), que examinaram a capacidade das crianças para consentir com pesquisas clínicas através do Instrumento de Avaliação de Competências MacArthur. ${ }^{7}$

Hein et al. (2015b), ao analisarem os fatores que podem interferir na capacidade para consentir (idade, inteligência, gênero, experiência prévia com a doença, condição socioeconômica e etnia), concluíram que a idade é o fator que mais explica a variação na competência das crianças para consentir em pesquisas clínicas $(56,4 \%)$, seguida pelo desenvolvimento intelectual $(12,7 \%)$, o que diverge dos critérios apresentados por Outlon et al., (2016) haja vista que os outros fatores podem potencialmente ter uma contribuição causal, mas não explicam significativamente a variação da capacidade dos julgamentos. A condição socioeconômica representou apenas $1,5 \%$, seguida das porcentagens de $0,5 \%$ do gênero; $0,3 \%$ da experiência com a doença; e $0,1 \%$ da etnia.

A complexidade e o risco da decisão, inesperadamente, não demonstraram impacto sobre a capacidade para a tomada de decisão e, segundo os autores, isso se deu em virtude da explicação clara e em linguagem acessível dos procedimentos de pesquisa.

Os autores demonstraram empiricamente que, com o recurso do instrumento MacArthur, três faixas etárias podem ser utilizadas para classificar a capacidade de decisão de uma criança: na primeira, as

6 Embora as crianças, em geral, compreendam os procedimentos básicos da maioria das pesquisas, existe uma tendência em acreditar que os adultos estão orientados a agir sempre em seu benefício. Assim, muitas crianças podem não assimilar que os procedimentos da pesquisa não estão, necessariamente, direcionados a seu bem-estar individual (KUTHER; POSADA, 2004).

Trata-se de um método de entrevistas semiestruturadas, desenvolvido por Appelbaum e Grisso, em 2001, que avalia quatro aspectos fundamentais para a tomada de decisão (compreensão das informações sobre a natureza e procedimentos da pesquisa; raciocínio no processo de decidir sobre a participação; apreciação dos efeitos da participação sobre a situação do paciente; e apresentação da escolha sobre a participação) (HEIN et al., 2015). 
crianças são provavelmente incompetentes; na segunda faixa etária, que envolve crianças entre 9,6 e 11,2 anos, a capacidade é menos clara, pois as crianças desse grupo desenvolvem capacidades importantes, mas sua maturidade não é abrangente; na terceira faixa, por fim, encontram-se as crianças com mais de 11,2 anos, que são provavelmente capazes.

Os resultados dessa pesquisa não prescrevem como, de acordo com a ética ou o Direito, devem lidar com as crianças no contexto da pesquisa clínica, mas tais dados podem ajudar a fazer justiça às capacidades que elas possuem. De acordo com Hein et al. (2015a), o consentimento informado e não o assentimento é apropriado para as crianças a partir dos 12 anos de idade.

Assim, do ponto de vista normativo, os legisladores poderiam assumir que crianças a partir dessa faixa etária podem consentir, o que afastaria o ônus de uma avaliação individual. Hein et al. (2015a), entretanto, propõem um procedimento de consentimento duplo que, na prática da pesquisa clínica, implicaria em duas versões de formulários, uma para os responsáveis legais e outra para a criança. Esse procedimento difere-se do modelo de consentimento dos responsáveis legais e do assentimento da criança, pois, na proposta de Hein et al.(2015a), ambos possuem o mesmo peso legal. Em hipótese de discordância e tendo sido esgotados todos os meios para se chegar a um acordo, Hein et al. (2015a) aceitam a prevalência do consentimento dos pais em favor da pesquisa apenas quando o objetivo é prevenir sério dano ou ter acesso a um tratamento importante não existente fora do contexto da pesquisa. As soluções apresentadas pelos autores, entretanto, parecem contraditórias, pois, uma vez verificada que a criança reúne todas as habilidades necessárias para expressar seu consentimento, sua decisão deve prevalecer em respeito ao exercício da sua autonomia.

Assim, o reconhecimento da capacidade sanitária da criança a partir dos 12 anos de idade para consentir, fato empiricamente comprovado anteriormente, exige que sua decisão seja sempre respeitada, ainda que pareça imprudente ou insensata.

\section{Conclusão}

De acordo com a Convenção sobre os Direitos da Criança (ONU, 1989), as crianças podem participar das pesquisas clínicas desde que forneçam seu assentimento ou consentimento.

Em reconhecimento à capacidade sanitária, o assentimento é um processo que permite a criança compreender o que será realizado em seu corpo, de acordo com o grau de sua maturidade. Internacionalmente, tem-se advogado a idade de 7 anos para assentir. Os menores de 7 anos, ainda que não tenham capacidade para o assentimento, serão ouvidos e sua opinião tomada com a devida consideração. Observou-se, através de estudo empírico recente, que, no contexto da pesquisa, as crianças podem ser consideradas competentes a partir dos 12 anos. Nesse caso, o consentimento, ao invés do assentimento, seria apropriado, pois uma vez que a criança reúne aptidões que comprovam a sua capacidade de consentir, sua decisão deverá ser acatada, independente de eventual oposição dos pais.

Ainda que, no Brasil, o assentimento esteja previsto apenas em resolução do Conselho Nacional de Saúde e não haja lei acerca do assentimento e consentimento das crianças em pesquisa clínica, sustenta-se a sua observância de forma vinculativa no contexto da pesquisa clínica, em consonância com o comando derivado da Convenção que assegura à criança o direito à participação.

O assentimento e o consentimento das crianças devem se tornar não apenas uma exigência ética, mas uma obrigação jurídica dos pesquisadores. O corpo da criança, enquanto participante de pesquisa, não pode ser objeto de decisão a partir dos valores e julgamentos realizados por terceiros.

\section{Referências}

ALBUQUERQUE, Aline. Assentimento da criança para participar de pesquisa sob a ótica da sua capacidade sanitária. Rev. Redbioética UNESCO, Montevideo, año 7, v. 2, n. 14, p. 19-30, jul./dic. 2016. 
BAINES, Paul. Assent for children's participation in research is incoherent and wrong. Arch. Dis. Child., London, v. 10, n. 96, p. 960-962, 2011.

BOCANEGRA, Eduardo Emilio Carsi. Deber profesional de obtener el asentimiento del niño para participar como sujeto de investigación. Boletim Médico del Hospital Infantil de México, Cidade do México, v. 67, p. 306-314, jul./ago. 2010.

BRASIL. Ministério da Saúde. Resolução $n^{\circ} 466$ do Conselho Nacional de Saúde, 12 de dezembro de 2012. [Brasília], 2012. Disponível em: http://bvsms.saude.gov.br/bvs/saudelegis/cns/2013/ res0466_12_12_2012.html. Acesso em: 29 maio 2018.

COUNCIL FOR INTERNATIONAL ORGANIZATIONS OF MEDICAL SCIENCES. International Ethical Guidelines for Biomedical Research Involving Human Subjects. Genebra: CIOMS, 2016.

DONNELLY, Mary. Healthcare decision-making and the law: autonomy, capacity and the limits of liberalism. New York: Cambridge University Press, 2010.

FLEISCHMAN, Alan R. Pediatric ethics: protecting the interests of children. New York: Oxford, 2016.

HERRING, Jonathan. Medical law. New York: Oxford University Press, 2011.

HEIN, Irma M. et al. Informed consent instead of assent is appropriate in children from the age of twelve: Policy implications of new findings on children's competence to consent to clinical research. BMC Medical Ethics, London, v. 16, n. 76, p. 1-7, 2015a.

HEIN, Irma M. et al. Key factors in children's competence to consent to clinical research. BMC Medical Ethics, London, v. 16, n. 24, p. 1-6, 2015b.

KUTHER, Tara L.; POSADA, Margarita. Children and adolescents capacity to provide informed consent for participation in research. Advances in Psychology Research, [S. I.], v. 32, p. 161-171, Feb. 2004.

MORENO, Jonathan D.; KRAVITT, Alexandra. The ethics of pediatric research. In: MILLER, Geoffrey

(org.). Pediatric bioethics. New York: Cambridge University Press, 2010. p. 54-72.

ORGANIZAÇÃO DAS NAÇÕES UNIDAS. Convenção sobre os Direitos da Criança. Disponível em: https://www.unicef.org/brazil/pt/resources_10120.htm. Acesso em: 26 mar. 2018.

ORGANIZAÇÃO DAS NAÇÕES UNIDAS. General comment $n^{\circ} .5$ : General measures of implementation of the Convention on the Rights of the Child. Committee on the Rights of the Child, 2003. Disponível em: http://tbinternet.ohchr.org/_layouts/treatybodyexternal/TBSearch. aspx? Lang=en\&TreatyID=5\&DocTypeID=11. Acesso em: 26 mar. 2018.

ORGANIZAÇÃO DAS NAÇÕES UNIDAS. General Comment $n^{\circ} .12$ : the right of the child to be heard. [S. I.]: Committee on the Rights of the Child, 2003. Disponível em: http://tbinternet.ohchr.org/_layouts/ treatybodyexternal/TBSearch.aspx? Lang=en\&TreatyID=5\&DocTypeID=11. Acesso em: 26 mar. 2018.

OULTON, K. et al. Assent for children's participation in research: why it matters and making it meaningful. Child: care, health and development, [S. I.], v. 42, n. 4, p. 588-597, 2016.

TAIT, Alan R.; GEISSER, Michael E. Development of a consensus operational definition of child assent for research. BMC Medical Ethics, London, v. 18, n. 41, p. 1-8, 2017.

ORGANIZAÇÃO DAS NAÇÕES UNIDAS PARA A EDUCAÇÃO, A CIÊNCIA E A CULTURA (UNESCO). Declaração Universal de Bioética e Direitos Humanos. Lisboa: UNESCO, 2006.

WENDLER, D. S. Assent in pediatric research: theoretical and practical considerations. Journal of Medical Ethics, London, n. 32, p. 229-234, 2006.

Recebido em: 30/05/2018

Aprovado em: 03/09/2108 